\title{
Chemical industry disasters and the sectoral transmission of financial market contagion
}

\author{
Shaen Corbet $^{a *}$, Charles Larkin ${ }^{b}$, Caroline McMullan ${ }^{a}$ \\ ${ }^{a}$ DCU Business School, Dublin City University, Dublin 9 \\ ${ }^{b}$ Trinity Business School, Trinity College Dublin, Dublin 2 \\ *Corresponding Author: shaen.corbet@dcu.ie
}

\begin{abstract}
Industrial incidents causing injury and fatality generate substantial costs to publicly traded firms. Risks associated with these potential incidents are not limited to only those companies that might be directly involved. Theoretically, stock markets are designed to self-regulate safety standards by decreasing company valuations should an incident occur, due to anticipated increased costs. This paper examines the sectoral consequences of such incidents in the United States, that is, the spillover effects of an industrial incident on firms operating in similar industrial operations. This is identified through the transmission of contagion within stock market sectors at the time of such incidents using a dynamic conditional correlation (DCC) multivariate GARCH methodology. The results indicate larger incidents, as measured by the number of injuries and fatalities, generate the largest contagion effects. Also, smaller competitor companies experience the largest contagion as measured by volatility effects as a result of sectoral chemical incidents, indicating that investors perceive increased risk factors and/or additional regulatory costs when valuing these companies in the period thereafter. We hypothesise that the observed reaction originates from expected increases in future sectoral operating costs through anticipated legislative and/or regulatory changes as well as uncertainty in the period immediately after an incident.
\end{abstract}

Keywords: Dynamic correlation, DCC-GARCH, Contagion, Industrial incident, Crisis management, Stock markets. 


\section{Introduction}

Investors and markets are quick to respond to new information and take it into account when assessing risks and returns on investments. Often studies focus only on the companies that experienced the industrial incident while neglecting to study the impact of this incident on the wider sector. However, the damage from organisational crises like industrial incidents may not be limited to just the incident company and the impact of an event in one corporation may be felt across a cluster of co-located businesses or even an entire sector. This impact may be evidenced by reputational damage, a loss of consumer confidence, an increase in regulation, a move towards competing products and, of course, a financial impact. From a financial perspective contagion may refer to the 'spillover effects of an economic shock from one firm to others, typically others in the same industry' (Kalra et al. [1995]). Studies of this contagion effect have been undertaken in the aftermath of the 1982 Tylenol crisis (Dowdell et al. [1992]), the Bhopal disaster (Kalra et al. [1995]) and the Fukushima nuclear accident (Basse Mama and Bassen [2013]).

Since risk can be generated internally or externally, effective risk management begins with an assessment of the key hazards facing an organisation. One method of identifying risk factors, for publicly traded companies, is to measure the impact of an event (external or internal to the organisation) on the stock prices of the company. Methodologies for measuring this impact have evolved. The DCC-GARCH model, developed by Engle [2002], was found to significantly improve upon the Constant Conditional Correlation (CCC)-GARCH model developed by Bollerslev [1986]. This improvement stemmed from the relaxation of the constant correlation assumption by allowing time-varying correlation. The number of unknown parameters was also limited in the DCC-GARCH model. The main advantage of using this type of approach is the detection of time-varying conditional correlations, which captures dynamic investor behaviour in response to news and innovations and to corporate crises and the subsequent response by the organisation. Contagion effects due to herding behaviour and flights to quality ${ }^{1}$ during turmoil periods can also be uncovered through these mechanisms (Syllignakis and Kouretas [2011]).

Forbes and Rigobon [2002] define contagion as a 'significant increase in the cross-market correlation during a turmoil period'. Therefore, it is necessary to compare the correlation between

\footnotetext{
${ }^{1}$ A flight to quality occurs when investors move their capital away from riskier investments to the safest possible investment vehicles. It is usually caused by uncertainty in international financial markets.
} 
stock markets during the pre-crises period to the period of time defined as 'being in-crisis'. If two markets are moderately correlated during the period of stability, and a shock to one market leads to a significant increase in market co-movements, this can be defined as financial contagion. However, if two markets are moderately correlated during the two periods, this can sometimes be attributed to market interlinkages rather than contagion (Mighri and Mansouri [2013]). It is necessary to segregate these two financial market phenomena. The application of the DCC-GARCH models has recently become a key focus of financial econometrics as the threat of widespread contagion increased. This model can be used to shed light on underlying questions based on the time-varying effects of correlation within competitor firms and the chemical sector at large, the effects on stock market correlations during periods of crises, or indeed contagion effects stemming from a chemical incident.

Our paper contributes to the empirical literature by showing that expectation of penalties, fines and regulatory or legal punishment for firms that experience chemical incidents that result in injuries and fatalities are reflected in the stock market reaction to the news of such incidents. Similar stock price reaction is also found in the stock prices of the incident companies' main competitors indicating that the financial market expects increased regulatory burden across the sector. It may also suggest that markets attach a greater uncertainty to the entire sector in the aftermath of an incident because it is initially unable to identify firms that are more likely to have a similar incident. Our focus makes this paper unique with regard to literature on the financial costs in the aftermath of chemical incidents.

The outline for the rest of this paper is as follows. Section 2 discusses the relevant previous literature. In Section 3, we discuss the model and our empirical framework. Section 4 describes the data and in Section 5, we present the results. Section 6 concludes the paper.

\section{Previous Literature}

There have been multiple attempts to quantify the effects on stock markets from a variety of incidents in recent times. Industrial incidents have received much attention along with legal and reputational costs as a result of product recalls. Chemical incidents remain an important focus, particularly given the potential for significant long-term human, environmental and legal cost. Salinger [1992] and Herbst et al. [1996] investigate the stock market response to catastrophes 
such as the Bhopal chemical explosion ${ }^{2}$ and the Exxon-Valdez oil spill ${ }^{3}$ and show that in the first month following those two major incidents, abnormal losses range between -12\% (Exxon-Valdez oil spill) and -30\% (Bhopal explosion). Capelle-Blancard and Laguna [2010] examine the stock market reaction to industrial disasters between 1990 and 2005 and show that petrochemical firms experience a drop in market value of $1.3 \%$ over the two days immediately following the disaster. The authors present evidence indicating that this loss is significantly related to the seriousness of the incident as measured by the number of casualties and by chemical pollution. The authors find that each casualty corresponds to a loss of $\$ 164$ million and a toxic release results in a loss of approximately $\$ 1$ billion.

Scholtens and Boersen [2011] investigate the short-term response of stock markets to energy accidents analysing 209 energy accidents in the period 1973 to 2007 . The authors find that the stock market does not show a significant short-term reaction regarding energy accidents; such accidents appear to be viewed as a 'normal' part of doing business in the eyes of financial markets. Ferstl et al. [2012] investigate the impact of the Japanese nuclear disaster in Fukushima-Daiichi on the daily stock prices of French, German, Japanese and US nuclear utility and alternative energy firms using a three-factor model through joint tests by multivariate regression models and bootstrapping. Significant abnormal returns are uncovered for Japanese, French and German firms. Investigating the same incident, Kawashima and Takeda [2012] find that stock prices of firms with nuclear power plants decline sharply after the incident. Whether or not the firms used the same type of reactors as those at Fukushima station does not affect stock prices. The authors observe an increase of both systematic and total risks in the post-Fukushima period, indicating that negative reactions are caused by structural changes in society and regulation. Konar and Cohen [2001] report on a study that relates the market value of firms in the S\&P500 to objective measures of their environmental performance. The authors find that bad environmental performance is negatively correlated with the intangible asset value of firms. In fact, a 10\% reduction in emissions of toxic chemicals results

\footnotetext{
${ }^{2}$ The Bhopal disaster, also referred to as the Bhopal gas tragedy, was a gas leak incident in India, considered the world's worst industrial disaster. It occurred on the night of 2 December 1984 at the Union Carbide India Limited (UCIL) pesticide plant in Bhopal, Madhya Pradesh. Over 500,000 people were exposed to methyl isocyanate (MIC) gas and other chemicals. The official death toll 3,787.

${ }^{3}$ The Exxon Valdez oil spill occurred in Alaska, March 24, 1989, when Exxon Valdez, an oil tanker owned by Exxon Shipping Company, spilled 10.8 million US gallons of crude oil. It is considered to be one of the most devastating human-caused environmental disasters. The oil eventually covered 1,300 miles $(2,100 \mathrm{~km})$ of coastline, and 11,000 square miles $\left(28,000 \mathrm{~km}^{2}\right)$ of ocean.
} 
in a $\$ 34$ million increase in market value.

Other event-studies of note include Kong [2012], who studies the melamine contamination incident in China to determine how investors respond to corporate social responsibility events in China, where long term financial benefits can be obtained through increasing focus on social responsibility. Salin and Hooker [2001] observe mixed volatility effects from stock market reaction to food recalls. $\mathrm{Xu}$ et al. [2012] investigate the stock market's reaction to information disclosure of environmental violation events in China. The authors estimate that the average reduction in market value is much lower than the estimated changes in market value for similar events in other countries, demonstrating that the negative environment events of Chinese listed companies currently have weak impacts on the stock markets. Coleman [2011] examined market efficiency in a natural environment using minute-by-minute share prices following industrial disasters causing fatalities and sudden Chief Executive Officer (CEO) deaths. Prices of affected firms start to react within an hour of shock events and fall by $3 \%$, but half of this fall is reversed prior to the first media reports with the balance reversed by the next trading day. The author interprets this as market overreaction as risk-averse investors respond to uncertainty created by the shock, prices returning to pre-shock levels once it is clear that the event is not worse than the expectations already built into valuations. Arin et al. [2008] investigate the effects of terrorism on stock market returns and volatility. Using six different financial markets, they show that terror has a significant impact on both stock markets and the stock market volatility, and the magnitude of these effects are larger in emerging markets. Blose et al. [1996] examine the stock returns experienced by NASA contractors associated with the Challenger Space Shuttle explosion and find significantly negative average abnormal returns on the shares of NASA contractors.

There is much literature on financial contagion as a result of economic crises. This same literature has moulded our approach when quantifying the contagion effects created through chemical incidents. King and Wadhwani [1990] and Yang and Bessler [2008] investigate the October 1987 US stock market collapse and find clear evidence of contagion channels during the stock market collapse. The East Asian crisis received similar attention. Masih and Masih [1999] find evidence of leadership of US stock markets over East Asian markets in both the short-term and long-term. Caporale et al. [2005] test for contagion within the East Asian region using a parameter stability test. They find that contagion effects were present in the selected sample, consistent with crisis-contingent theories of asset market linkages. Khan and Park [2009] also find strong evidence of herding contagion when 
analysing time-varying correlation coefficients for the same sample of countries.

Kenourgios et al. [2011] investigate financial contagion in a multivariate time-varying asymmetric framework, focusing on four emerging stock markets (Brazil, Russia, India, and China) and two developed markets (US and UK). The authors use a multivariate regime-switching Gaussian copula model and the asymmetric generalised dynamic conditional correlation (AG-DCC) approach on data between 1999 and 2006, uncovering confirmation that contagion effects transfer from designated crisis countries to all other countries. Developing countries are also more prone to financial contagion, with industry-specific turmoil having a larger impact than country-specific crises. Markwat et al. [2009] show that stock market contagion occurs as a domino effect, where confined local crashes evolve into more widespread crashes. Using ordered logit regressions, the authors find significant evidence that global crashes do not occur abruptly but are preceded by local and regional crashes. Karanasos et al. [2014] examine the impact of financial crises on various stock market indexes. They show the existence of dynamic correlations and time varying volatility spillovers.

Forbes and Rigobon [2002] present evidence indicating that correlation coefficients are conditional on market volatility, and under certain assumptions, it is possible to adjust for this bias. Using this adjustment, the authors find that there was virtually no increase in unconditional correlation coefficients (thus no contagion) during the 1997 Asian crisis, 1994 Mexican devaluation and the 1987 US market crash. The authors find a high level of market co-movement in all periods investigated, but denote this as interdependence. Similarly, Rodriguez [2007] models dependence with switching-parameter copulas to study financial contagion using daily returns from five Eastern Asian stock indices during the Asian crisis and from four Latin American stock indices during the Mexican crisis. Evidence is uncovered of changing dependence during periods of turmoil. Structural breaks in tail dependence are found to be a dimension of contagion phenomenon.

Numerous econometric approaches have been used to quantify the effects of industrial incidents. One of the most popular methodologies is that using a GARCH methodology. Wang et al. [2002] investigate stock market reaction to food recalls in this manner to uncover time-varying volatility in the series as a result of food recalls due to bacterial contamination. The authors find that the initial food recall undertaken by the company is associated with reduced mean returns and higher volatility of the companies included in the study, with volatility across firms suggesting potentially industry-wide repercussions due to these incidents. Using a similar GARCH methodology with the addition of exogenous variables (GARCH-X), Shah et al. [2009] investigate exchange rate volatility 
after Central Bank intervention in Pakistan and show that intervention operations are very effective as they not only affect exchange rate levels, but also reduce exchange rate volatility.

Ramchand and Susmel [1998] investigate volatility and cross correlation across major international stock markets using a switching $\mathrm{ARCH}(\mathrm{SWARCH})$ technique. The authors find that the correlations between the US and other world markets are on average 2 to 3.5 times higher when the US market is in a high variance state as compared to a low variance regime. The SWARCH model is also found to lead to higher Sharpe ratios. Ahlgren and Antell [2010] use co-breaking to model co-movements between stock markets during crises and to test for contagion. The authors find evidence of co-breaking between developed stock markets and the main evidence of co-breaking in emerging stock markets is found at the time of the 9/11 terrorist attacks in 2001. Short-term linkages during times of crisis are uncovered but there was no evidence of contagion.

In this paper, we extend the GARCH methodology and use a Dynamic Conditional Correlation (DCC) Multivariate GARCH methodology, to specifically investigate the contagion effects caused by our sample of chemical incidents. The DCC-GARCH model, developed by Engle [2002], significantly improves upon the Constant Conditional Correlation (CCC)-GARCH model developed by Bollerslev [1990] by capturing dynamic investor behaviour in response to news and innovations. Contagion effects due to herding behaviour and flights to safety during turmoil periods can also be uncovered through these mechanisms (Syllignakis and Kouretas [2011]).

\section{Methodology}

In this analysis, we employ a multivariate GARCH model with Dynamic Conditional Correlation (DCC) that allows for time-varying conditional correlation as proposed by Engle [2002]. In a first step, we specify the mean equation as follows:

$$
r_{t}=\mu_{1} r_{t-1}+\mu_{2} r_{t-2}+\mu_{3} r_{t}^{C 1}+\mu_{4} r_{t}^{C 2}+\mu_{5} r_{t}^{C 3}+\mu_{6} r_{t}^{D J I A}+\varepsilon_{t}
$$

where $r_{t}=\left(r_{1 t}, r_{2 t}, \ldots, r_{n t}\right)^{\prime}$ and $\varepsilon_{t}=\left(\varepsilon_{1 t}, \varepsilon_{2 t}, \ldots, \varepsilon_{n t}\right)^{\prime}$. Also, $\epsilon_{t}=H_{t}^{1 / 2} z_{t}$ and $\epsilon_{t} / F_{t-1} N\left(0, H_{t}\right)$. $z_{t}:(n x 1)$ is denoted as a vector of i.i.d. errors such that $E\left(z_{t}\right)=0$ and $E\left(z_{t}, z_{t}^{\prime}\right)=1$. Finally, $H_{t} \equiv h_{i j_{t}} \forall i, j=1,2, \ldots, n$ is an ( $\mathrm{n} \times \mathrm{n}$ ) matrix of conditional variances and covariances of $r_{t}$ conditional to previous returns. In the mean equation, we include an $\operatorname{AR}(1)$ term and the one and two-day lagged equity returns as a measure of the impact of the company experiencing the 
industrial accident upon companies trading in a similar industry or sector. The term $\mu_{n} r_{t}^{C n}$ is added to test the impact of $r_{t}$ upon company $\mathrm{n}$ at time $\mathrm{t}$. This term measures the direct impact and the sign of the relationship between the equity market returns of the two companies during the period of investigation. The term $r_{t}^{D J I A}$ is added as an explanatory factor related to external events not related to chemical incidents, that is, the effects of the Dow Jones Industrial Average on the DCC-GARCH methodology. This is designed to obtain estimates as closely related to the chemical incident company and the transmission of contagion effects while eliminating as much of the effects of other non-related crises as possible. We then specify a multivariate conditional variance as: $H_{t} \equiv D_{t} R_{t} D_{t}$ where $R_{t}=\rho_{i j t}$ is an (n x n) conditional symmetric correlation matrix of $\epsilon_{t}$ at time $\mathrm{t}$ and $D_{t}=\operatorname{diag} \sqrt{h_{i t}}$ is an $(\mathrm{n} \times \mathrm{n})$ diagonal matrix of conditional standard deviations of $\epsilon_{t}$ at time t. The elements in the diagonal matrix $D_{t}$ are the standard deviations from univariate GARCH models:

$$
h_{i t}=\omega_{i}+\Sigma_{i=1}^{q} \alpha_{i} \epsilon_{t-1}^{2}+\Sigma_{j=1}^{p} \beta_{j} h_{t-j}
$$

where $\omega_{i}>0 ;{ }_{i} \geq 0 ; \beta_{j} \geq 0$ and $\Sigma_{i=1}^{q} \alpha_{i}+\Sigma_{j=1}^{p} \beta_{j}<1$. The elements of $H \equiv D_{t} R_{t} D_{t}$ are $\left[H_{t}\right]_{i j}=\sqrt{h_{i j} h_{j t}} \rho_{i j, t}$. As proposed by Engle (2002), the DCC-GARCH model is designed to allow for a two-stage estimation of the conditional variance matrix $h_{t}$. In the first stage, univariate GARCH $(1,1)$ volatility models are fitted for each of the stock return residuals and estimates of $\sqrt{h_{i t}}$ are obtained. In the second stage, stock return residuals are transformed by their estimated standard deviations from the first stage as $z_{i t}=\frac{\epsilon_{i t}}{\sqrt{h_{i t}}}$. Then, the standardised residual $z_{i t}$ is used to estimate the correlation parameters. The dynamics of the correlation in the standard DCC-GARCH model could be expressed as follows:

$$
Q_{t}=(1-a-b) \bar{Q}+a z_{t-1} z_{t-1}^{\prime}+b Q_{t-1}
$$

where $a \geq 0, b \geq 0$ and $\left.a+b<1 . Q_{t}=\left[q_{(} i j, t\right)\right]$ is the time-varying covariance matrix of $z_{t}$ and $\bar{Q}=E\left(z_{t}, z_{t}^{\prime}\right)$ is a (nx n) unconditional covariance matrix of $z_{t}$. In addition, $Q_{0}$, the starting value of $Q_{t}$ should be positive to guarantee that $H_{t}$ would also be positive. In a bivariate setting, the conditional covariance could be expressed as follows:

$$
q_{i j, t}=\left(1-a_{i, j}-b_{i, j}\right) \bar{q}_{i j}+a_{i j} z_{i, t} z_{j, t-1}+b_{i j} q_{i j, t-1}
$$


When specifying the form of the conditional correlation matrix $R_{t}$, two requirements have to be considered. The first is that the covariance matrix $H_{t}$ has to be positive and the second is that all the elements in the conditional correlation matrix $R_{t}$ have to be equal or less than unity. To ensure both of these requirements in the DCC-GARCH model, the correlation matrix $R_{t}$ could be decomposed as:

$$
\begin{gathered}
R_{t}=Q_{t}^{*-1 / 2} Q_{t} Q_{t}^{*-1 / 2} \\
\text { where } Q_{t}^{*}=\operatorname{diag}\left(Q_{t}\right)=\left[\begin{array}{ccc}
\sqrt{q_{1,1, t}} & \cdots & 0 \\
\vdots & \ddots & \vdots \\
0 & \cdots & \sqrt{q_{m, n, t}}
\end{array}\right] \text { and } R_{t}=\left[\begin{array}{ccc}
1 & \cdots & \rho_{1, n, t} \\
\vdots & \ddots & \vdots \\
\rho_{1, n, t} & \cdots & 1
\end{array}\right] \text { is a correlation }
\end{gathered}
$$

matrix with ones on the diagonal and off-diagonal elements are less than one in absolute value as long as Q_t is positive. The correlation coefficient can therefore be expressed as: $\rho_{i j, t}=$ $\frac{q_{i j, t}}{\sqrt{q_{i i, t} \sqrt{q_{j j, t}}}} \forall i, j=1,2, \ldots, n ; i \neq j$. As noted by Engle [2002], the DCC model could be estimated by using a two-step approach to maximise the log-likelihood function. If we let $\theta$ denote the parameters in $D_{t}$ and $\vartheta$, the parameters in $R_{t}$, then the log-likelihood is:

$$
l_{t}(\theta, \vartheta)=\left[-\frac{1}{2} \Sigma_{t=1}^{T} n \log (2 \pi)+\log \left|D_{t}\right|^{2}+\varepsilon_{t}^{\prime} D_{t}^{-2} \varepsilon t\right]+\left[\Sigma_{t=1}^{T} \log \left|R_{t}\right| z_{t}^{\prime} R_{t}^{-1} z_{t}-z_{t}^{\prime} z_{t}\right]
$$

The first part of the log likelihood function is volatility, which is the sum of the individual GARCH likelihoods. The log-likelihood function can be maximised in the first stage over the parameters $D_{t}$. Given the estimated parameters in the first stage, the correlation component of the likelihood function in the second stage is maximised to estimate the correlation coefficients. Finally, we examine the DCC-GARCH model's change in behaviour before and after a chemical incident occurs. In a first stage analysis, we estimate the impact of external shocks on the dynamic conditional correlation features. The influence of the chemical incident has some particularly interesting effects. Through the use of a dummy variable denoting the date of the chemical incident enables us to investigate the dynamic features of the correlation coefficient changes associated with the incident, in terms of the pairwise correlations between the related companies' equity markets investigated and that of the incident company. We regress the time-varying correlation model as follows: 


$$
\rho_{i j, t}=\omega_{i j}+\Sigma_{p=1}^{p} \varphi_{p} \rho_{i j, t-p}+\Sigma_{k=1}^{2} \alpha_{k} D M_{k, t}+\varepsilon_{i j, t}
$$

where $\rho_{i j, t}$ is the pair-wise conditional correlation coefficient between the stock return $\mathrm{i}$ of the incident company and the stock returns $\mathrm{j}$ of the three largest sectoral trading partners. $D M_{1}$ is a dummy variable denoting the date of the chemical incident, thus indicating the expected onset of sectoral contagion. The value of the dummy variables are set equal to unity for the period after the chemical incident and zero otherwise. We use the Akaike Information Criterion (AIC) and Schwarz Bayesian Information Criterion (SBIC) to determine the lag length of the above equation. From the descriptive statistics of the time-varying correlation series, we find significant heteroskedasticity in all cases using the White test which allows the independent variable to have a nonlinear and interactive effect on the error variance ${ }^{4}$. Therefore, the conditional variance equation is assumed to follow a $\operatorname{GARCH}(1,1)$ specification including a dummy variable identifying the exact date of the incident, $D M_{k}(k=1)$ :

$$
h_{i, t}=A_{0}+A_{1} \varepsilon_{t-1}^{2}+B_{1} h_{i, t-1}+\Sigma_{k=1}^{2} d_{k} D M_{k, t}
$$

where $A_{0}>0, A_{1} \geq 0, B_{1} \geq 0$ and $A_{1}+B_{1}<1$. In the mean equation, the coefficient $d_{1}$ is statistically significant in all the incidents investigated.

We use the Akaike Information Criterion (AIC) and Schwarz Bayesian Information Criterion (SBIC) to determine the lag length of the above equation. From the descriptive statistics of the time-varying correlation series, we find significant heteroskedasticity in all cases. The results are discussed in section 5 .

\section{Data}

This paper investigates industrial incidents in the United States between January 2000 and May 2014. After implementing an analysis of all industrial incidents from the United States Chemical Safety Board (CSB) database, a search of the LexusNexis database using a variety of keywords was conducted. The keywords used were chemical incident, industrial incident, pharmaceutical incident,

\footnotetext{
${ }^{4}$ We used the White Test (White [1980]) to determine as to whether there exists heteroskedasticity in our selected methodological specification. Heteroskedasticity-consistent standard errors can be used if homoskedasticity is rejected.
} 
oil incident and gas incident, and all keywords were combined with the words spill, explosion, fire, accident. This method provided a sample of 179 individual incidents involving substantial property damage, injury and/or deaths that involved publicly traded companies. The next stage was to find the closest trading competitors of the identified incident companies (at the time of the incident). A further search of financial markets using criteria including company size, business origins, location, number of employees, revenues and range of products was used to identify suitable competitors to analyse. The results of this analysis and the companies used in the corresponding contagion analysis are found in Table 1.

\section{Insert Table 1 about here}

The financial market data in this study comes from Bloomberg and Thompson Reuters DataStream. Due to data limitations the final sample reduced to 60 individual chemical incidents from which results based on contagion effects could be obtained. This reduction occurred as a result of significant market illiquidity, which resulted in mispricing which deemed the GARCH-methodology to be insignificant. There were also issues with some companies of gaps in the data, created during takeovers or when a company was in the process of being taken over. In this situation, the stock price of the current parent company was deemed inappropriate for use as there was no connection between the parent company and the incident company at the time of the chemical incident. The resulting companies can be found in tables 2, 3 and 4, with the associated stock market tickers, the date and place of the incident along with the number of injuries and fatalities associated with each event. The incidents are further subcategorised based on the findings of the US CSB, for which incidents are denoted as caused by company violations and safety errors, equipment failure or vandalism. These designated outcomes were identified after substantial analysis and scrutiny of each event.

\section{Insert Tables 2 and 3 about here}

After substantial analysis, the four year period around each of the chemical incidents was chosen as the best period of investigation, that is two years before and two years after. As discussed in Section 3, the GARCH-methodology requires a significant amount of data to obtain significant 
interlinkages between the identified companies from which to obtain contagion estimates. As noted in Table 1, some companies had repeated chemical incidents during the period of investigation, and in this regard, the same corresponding companies remained, but the dummy variables identifying the incident period changed. Therefore, the results are specific to the incident.

\section{Insert Table 4 about here}

Proxies were also used to mitigate external factors as explained in Section 3. In this situation, the Dow Jones Industrial Average was used to mitigate as much of the numerous crises periods during the sample (2000-2014) were not related directly to chemical incidents. In this regard, the resulting contagion estimates are as closely related to the incident company and their direct competitors as possible. Data for this proxy was obtained from Bloomberg.

\section{Results}

Table 5 reports the estimates of the return and conditional variance equations as well as the DCC parameters modelled on industrial incidences caused by company violations and safety errors. Table 6 and 7 represent the parameter estimates for incidents caused by equipment failure and human error respectively. The constant terms in the mean equation $\left(\mu_{0}\right)$ are significantly different from zero for the majority of incidents. With the exception of three incidents (Models 2, 12 and 19), the $\mu_{1}$ and $\mu_{2}$ terms are significantly positive for the remaining markets. The negativity of the $\operatorname{AR}(1)$ term in the mean equation can be attributed to the existence of positive feedback trading, while the positivity can be attributed to price frictions and partial adjustment. $c_{1}, c_{2}$ and $c_{3}$ represent the correlation coefficients as modelled in the mean equation and in isolation. The correlation dynamics are explained in section three and are significant for all models with the exception of three (models 2, 11 and 27). These results identify the companies best represented as the closest trading rivals of the incident companies, thus indicating an appropriate sample from which to draw contagion results using the DCC-GARCH methodology. The findings indicate strong correlation dynamics between the industrial rivals.

The parameters $\alpha_{i}$ in the variance equations are statistically different from zero for all stock returns. The coefficients for the lagged variance $\left(\beta_{i}\right)$ are positive and statistically significant at the $1 \%$ level for all stock markets. This justifies the suitability of the DCC GARCH $(1,1)$ specification 
as the best fitting model to capture time-varying volatility. Moreover, the $\alpha_{1}+\beta_{1}$ is very close to unity in all the markets investigated, indicating a high short-term persistence of the conditional variance. Therefore, the volatility in the GARCH models displays a high persistence.

\section{Insert Tables 5, 6 and 7 about here}

Tables 5, 6 and 7 also reports the estimates of the bivariate $\operatorname{DCC}(1,1)$ model. The parameters $\alpha$ and $\beta$ of the $\operatorname{DCC}(1,1)$ models respectively capture the effects of standardised lagged shocks $\left(\epsilon_{t-1}, \epsilon_{t-1}^{\prime}\right)$ and the lagged dynamic conditional correlation effect $\left(Q_{t-1}\right)$ on current dynamic conditional correlation. The statistical significance of these coefficients in each pair of equity markets investigated indicates the existence of time-varying dynamic correlations. When $\alpha_{1}=0$ and $\beta_{1}=0$, we obtain Bollerslev [1990] Constant Conditional Correlation (CCC) model. The estimated coefficients $\alpha_{1}$ and $\beta_{1}$ are all positive and satisfy the inequality constraint of $\alpha_{1}+\beta_{1}<1$ in each of the pairs of stock markets investigated. As shown in Table 4 , the parameter $\alpha$ is statistically significant in all the pairs investigated. The parameter $\beta_{1}$ is also highly significant. The significance of both the DCC parameters reveals a considerable time-varying co-movement and thus a high persistence of the conditional correlation. The sum of these parameters are very close to unity, thus implying that the volatility displays a high level of persistence. Also, since $\alpha_{1}+\beta_{1}<1$, the dynamic correlations revolve around a constant level and the dynamic process appears to be mean reverting.

A $\operatorname{GARCH}(1,1)$ specification as seen in Equation 10 is used to identify the direct volatility impacts on competitor companies after an industrial incidents. Tables 8, 9 and 10 present the findings attributed to volatility impacts stemming from incidents caused by company violations, equipment failure and human error respectively. $\omega_{i j}, \alpha_{1}$ and $\beta_{1}$ present the GARCH coefficients which are significant at a minimum of the $10 \%$ level in all models except that of model 36. $D M_{1}$ presents the GARCH volatility change for the incident company. As theoretically expected, this coefficient is positive in all scenarios indicating increasing volatility in the period of the incident. The smallest incident response is for that of the Honeywell chemical leak in August 2003 of 0.01\%. The largest incident response is for the Imperial Sugar Company fire and explosion in February 2008 of $1.06 \%$. Represents $M C d_{i}$ represents the market capitalisation of contagion company 1,2 and 3 in the sample, where $d_{i}$ represent the GARCH calculated volatility estimate.

\section{Insert Tables 8, 9 and 10 about here}


Positive volatility changes are found in all correlation pairings investigated in the sample, indicating direct contagion effects between the incident company and its closest associated trading competitors. The smallest change is $0.01 \%$, whereas the largest is $0.99 \%$. Figure 1 presents the relationship between the GARCH volatility estimates of the chemical incident company and the estimate of GARCH volatility for the competitor company. There is a positive relationship identified in the results, thus indicating that larger chemical incidents, which are found to cause larger stock market volatility, transfer larger amounts of volatility to competitor companies. In other words, the most severe incidents as measured by the number of injuries and fatalities generate the largest contagion effects. Also in Figure 1, we observe the relationship between the GARCH volatility estimates for the incident company and the market capitalisation of the competitor companies included in the sample. There is a clear negative relationship, indicating that smaller companies, on average, experience larger volatility in their share price as a result of a competitor experiencing a chemical incident. This is a very interesting finding. Larger competitors in the same industry as the incident company experience an increase in volatility, but investors do not envisage the incident creating extremely negative long-term effects. Whereas, small companies can possess substantial exposures.

\section{Insert Figure 1 about here}

We hypothesise that this effect may be as a result of an observed risk from investors of increased legislative and/or regulatory changes as direct result of the chemical incident. Should this occur, it would add significant expense to the competitor company in the form of training, mitigation, and health and safety costs. Of course, this additional cost reduces the expected profit of future periods, therefore investors act accordingly and reduce their expectation of future profits. Even though the incident company itself may absorb the costs of the incident and continue their business practices as before, smaller companies may actually become entangled through contagion effects, placing emphasis on their viability and reducing the probability of long-term survival.

\section{Conclusions}

Risk of an industrial incident has implications not only for the company that experienced the incident but also for other companies in the same industrial sector due to the likelihood of increased, costly regulatory oversight and measures to reduce the chances of similar incidents occurring in the 
future. Overall, our results suggest that chemical incidents create significant contagion effects, where market correlations increase and appear persistent for a period of time thereafter. These increased correlations are consistent with a investors being less certain of the sector's future. The results indicate investor herding behaviour, as the incident company is directly impacted by a share price decrease, but investors appear to view the incident as possessing sectoral consequences. These results suggest interesting regulatory implications, both for self-regulation and regulatory policy. It may well be the case that companies within a sector need to monitor each other since 'the weakest link' (the company most prone to incidents due to internal shortcomings) in the sector will have an adverse effect on the entire sector.

Stock markets appear to adequately punish companies at fault for chemical incidents and the degree of punishment is affected by the reported cause of the incident. Not only has the incident company to consider the cost of the incident in both clean-up and rebuilding costs, along with litigation costs and environmental penalties, but it must also absorb reductions in market capitalisation as dictated by its share price. The findings of this paper present evidence that this effect is sectoral. Investors appear to view all companies in the same way, therefore including the increased risk of industrial penalties and regulatory/legislation changes in their valuations. The largest chemical incidents are associated with the largest contagion effects as measured by GARCH volatility. Interestingly, the smallest companies also produce the largest increases in volatility, indicating stock market sentiment that the validity of the company as a viable entity may be under threat, but this contagion effect also influences smaller competitors in the same manner. More research is needed to investigate the direct causes of this effect, but one could hypothesise that the potential regulatory changes and costs that may be incurred from additional mitigation, training and health and safety costs may have a significant influence.

\section{Bibliography}

Ahlgren, N. and J. Antell (2010). Stock market linkages and financial contagion: A co-breaking analysis. The Quarterly Review of Economics and Finance 50(2), 157-166.

Arin, K. P., D. Ciferri, and N. Spagnolo (2008). The price of terror: The effects of terrorism on stock market returns and volatility. Economics Letters 101(3), 164-167. 
Basse Mama, H. and A. Bassen (2013). Contagion effects in the electric utility industry following the Fukushima nuclear accident. Applied Economics 45(24), 3421-3430.

Blose, L. E., R. Bornkamp, M. Brier, K. Brown, and J. Frederick (1996). Catastrophic events, contagion, and stock market efficiency: The case of the space shuttle Challenger. Review of Financial Economics 5(2), 117-129.

Bollerslev, T. (1986). Generalized autoregressive conditional heteroskedasticity. Journal of Econometrics 31(3), 307-327.

Bollerslev, T. (1990). Modelling the coherence in short-run nominal exchange rates: A multivariate generalized arch model. The Review of Economics and Statistics 72(3), 498-505.

Capelle-Blancard, G. and M. A. Laguna (2010). How does the stock market respond to chemical disasters? Journal of Environmental Economics and Management 59(2), 192-205.

Caporale, G. M., A. Cipollini, and N. Spagnolo (2005). Testing for contagion: a conditional correlation analysis. Journal of Empirical Finance 12(3), 476-489.

Coleman, L. (2011). An exploratory analysis of factors influencing initial market response and media reports following shock corporate events. Financial Review 46(2), 313-336.

Dowdell, T. D., S. Govindaraj, and P. C. Jain (1992). The Tylenol incident, ensuing regulation and stock prices. Journal of Financial and Quantitative Analysis 27(2), 283-301.

Engle, R. (2002). Dynamic conditional correlation: A simple class of multivariate generalized autoregressive conditional heteroskedasticity models. Journal of Business and Economic Statistics 20(3), 339-350.

Ferstl, R., S. Utz, and M. Wimmer (2012). The effect of the Japan 2011 disaster on nuclear and alternative energy stocks worldwide: An event study. Business Research 5(1), 25-41.

Forbes, K. J. and R. Rigobon (2002). No contagion, only interdependence: Measuring stock market comovements. The Journal of Finance 57(5), 2223-2261.

Herbst, A. F., J. F. Marshall, and J. Wingender (1996). An analysis of the stock market's response to the Exxon Valdez disaster. Global Finance Journal 7(1), 101-114. 
Kalra, R., G. Henderson, and G. Raines (1995). Contagion effects in the chemical industry following the Bhopal disaster. Journal Of Financial And Strategic Decisions 8(2), 1-11.

Karanasos, M., A. G. Paraskevopoulos, F. Menla Ali, M. Karoglou, and S. Yfanti (2014). Modelling stock volatilities during financial crises: A time varying coefficient approach. Journal of Empirical Finance 29, 113-128.

Kawashima, S. and F. Takeda (2012). The effect of the Fukushima nuclear accident on stock prices of electric power utilities in Japan. Energy Economics 34 (6), 2029-2038.

Kenourgios, D., A. Samitas, and N. Paltalidis (2011). Financial crises and stock market contagion in a multivariate time-varying asymmetric framework. Journal of International Financial Markets, Institutions and Money 21(1), 92-106.

Khan, S. and K. W. K. Park (2009). Contagion in the stock markets: The Asian financial crisis revisited. Journal of Asian Economics 20(5), 561-569.

King, M. A. and S. Wadhwani (1990). Transmission of volatility between stock markets. The Review of Financial Studies 3(1), 5-33.

Konar, S. and M. A. Cohen (2001). Does the market value environmental performance? The Review of Economics and Statistics 83(2), 281-289.

Kong, D. (2012). Does corporate social responsibility matter in the food industry? Evidence from a nature experiment in China. Food Policy 37(3), 323-334.

Markwat, T., E. Kole, and D. van Dijk (2009). Contagion as a domino effect in global stock markets. Journal of Banking \& Finance 33(11), 1996-2012.

Masih, A. M. and R. Masih (1999). Are Asian stock market fluctuations due mainly to intraregional contagion effects? Evidence based on Asian emerging stock markets. Pacific-Basin Finance Journal 7(3), 251-282.

Mighri, Z. and F. Mansouri (2013). Dynamic conditional correlation analysis of stock market contagion: Evidence from the 2007-2010 financial crises. International Journal of Economics and Financial Issues 3(3), 637-661. 
Ramchand, L. and R. Susmel (1998). Volatility and cross correlation across major stock markets. Journal of Empirical Finance 5(4), 397-416.

Rodriguez, J. C. (2007). Measuring financial contagion: A copula approach. Journal of Empirical Finance 14(3), 401-423.

Salin, V. and N. H. Hooker (2001). Stock market reaction to food recalls. Review of Agricultural Economics 23(1), 33-46.

Salinger, M. (1992). Value event studies. The Review of Economics and Statistics 74(4), 671-677.

Scholtens, B. and A. Boersen (2011). Stocks and energy shocks: The impact of energy accidents on stock market value. Energy 36(3), 1698-1702.

Shah, M. K. A., Z. Hyder, and M. K. Pervaiz (2009). Central bank intervention and exchange rate volatility in Pakistan: An analysis using GARCH-X model. Applied Financial Economics 19(18), $1497-1508$.

Syllignakis, M. N. and G. P. Kouretas (2011). Dynamic correlation analysis of financial contagion: Evidence from the Central and Eastern European markets. International Review of Economics and Finance 20(4), 717-732.

Wang, Z., V. Salin, N. H. Hooker, and D. Leatham (2002). Stock market reaction to food recalls: A GARCH application. Applied Economics Letters 9(15), 979-987.

White, H. (1980). A heteroskedasticity-consistent covariance matrix estimator and a direct test for heteroskedasticity. Econometrica: Journal of the Econometric Society 48(4), 817-838.

Xu, X. D., S. X. Zeng, and C. M. Tam (2012). Stock market's reaction to disclosure of environmental violations: Evidence from China. Journal of Business Ethics 107(2), 227-237.

Yang, J. and D. A. Bessler (2008). Contagion around the October 1987 stock market crash. European Journal of Operational Research 184(1), 291-310. 
Figure 1: Incident GARCH volatility estimates compared with contagion GARCH volatility estimates and market capitalisation
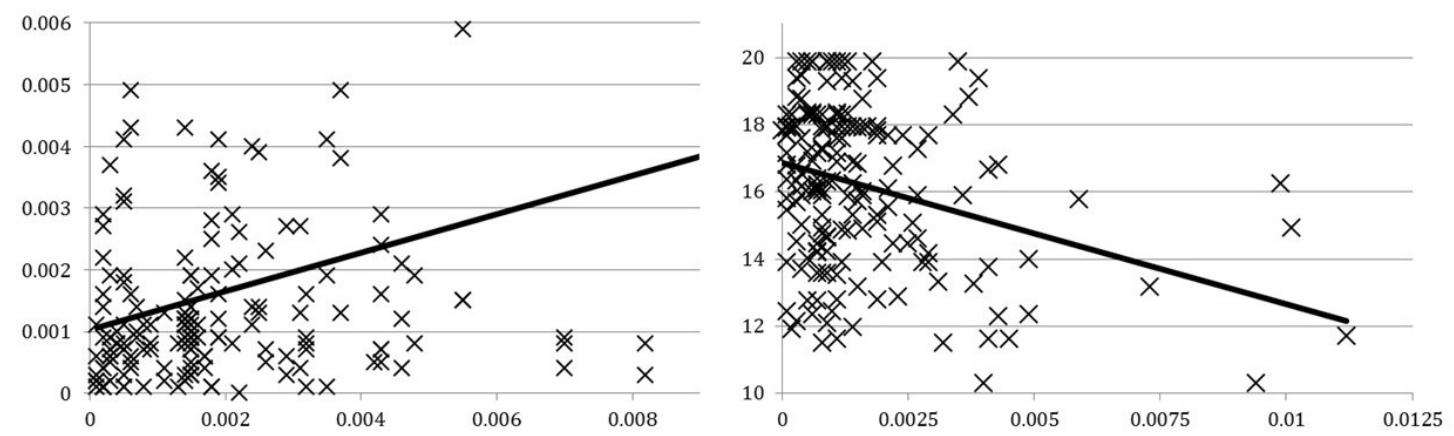

Note: The left-hand scatterplot represents the relationship between the GARCH volatility estimate of the incident company and that of the GARCH volatility of the competitor company. The right-hand scatterplot represents the relationship between the GARCH volatility estimate of the incident company and that of the market capitalisation (measured as the natural logarithm of market capitalisation measured in US\$ billion on the day of the chemical incident). 
Table 1: Stock market tickers for companies (ranked by market capitalisation) in the same sector as those who experienced an industrial accident.

\begin{tabular}{|c|c|c|c|c|}
\hline Causation company & Model & Related Co. 1 & Related Co. 2 & Related Co. 3 \\
\hline ABLE - Able Energy & 2 & DK & QDRSF & SGU \\
\hline BON - Bonduelle & 57 & $\mathrm{LD}$ & SUCO & WES \\
\hline BP - BP Oil & $4,8,17,22,38$ & CVX & $\mathrm{XOM}$ & âĂ \\
\hline BRK.A - Berkshire Hathaway & 25 & GE & UNP & WMT \\
\hline CAG - ConAgra Natural Gas & 13 & LSAL & PEP & TOF \\
\hline $\mathrm{CF}$ - CF Industries & 14 & RNF & $\mathrm{TNH}$ & UAN \\
\hline CVX - Chevron & 20,35 & $\mathrm{BP}$ & RDS.A & TOT \\
\hline CW - Arens Controls & 19 & CIR & MOG.A & MWA \\
\hline DCI - Donaldson Enterprises & 18 & CLC & CECE & FTEK \\
\hline DD - E.I. DuPont De Nemours Co & 15 & DOW & MON & HUN \\
\hline DEDR.L - Delek Refining & 11,45 & AVNR.L & IE & CDEV \\
\hline DHR - Dover Chemical Company & 34,48 & ALGN & SI & A \\
\hline DOW - Dow Chemical Company & $29,31,32,49$ & $\mathrm{XOM}$ & MON & DD \\
\hline EAGLU - Silver Eagle & 28 & PLAHF & ZPLSQ & $\mathrm{NMO}$ \\
\hline FDML - Federal Mogul Holdings Corp & 59 & DAN & GM & TRW \\
\hline GT - Goodyear & 26,58 & CTB & BRDCY & MGDDY \\
\hline HON - Honeywell & $21,40,41$ & UTX & BA & EMR \\
\hline IPSU - Imperial Sugar Co. & 9 & RAH & MTSSF & WWAY \\
\hline JAH - Mapa Spontex & 23 & PHG & $\mathrm{XNNH}$ & SAVW \\
\hline KRFT - Kraft Foods & 39 & MDLZ & PEP & SJM \\
\hline MCS - Marcus Oil & 43 & AMC & CKEC & RGC \\
\hline NLC - Nalco Holding & 49 & ARJ & WCAA & EIO \\
\hline NWSA - News Corp & 52 & GCI & $\mathrm{PSO}$ & CBS \\
\hline OAS - Oasis Petroleum & 33 & TPLM & EOX & BCEI \\
\hline OXY - Oxydental Chemical Corp. & 27 & PAA & CVX & $\mathrm{XOM}$ \\
\hline PKG - Packaging Corp of America & 10 & RKT & IP & MWV \\
\hline PXP - Plains Exploration & 42 & APC & CHK & âĂŞ \\
\hline SIAL - Sigma Aldrich & 3 & QGEN & TECH & APC \\
\hline TMO - Frontier Scientific & 24 & GE & PKI & HBIO \\
\hline TSN - Tyson Foods & 5 & HRL & SAFM & BRFS \\
\hline TSO - Tesoro & 16 & PSX & VLO & $\mathrm{HFC}$ \\
\hline UNP - Union Pacific & 44 & NSC & CSX & KSU \\
\hline VE - Veolia Environnement & 12 & GDFZY & AWK & SZEVF \\
\hline VLO - Valero Refineries & $6,36,46,53,57$ & ALJ & PSX & TSO \\
\hline WLK - Westlake Vinyls & 37 & AXLL & $\mathrm{XOM}$ & EMN \\
\hline WSHP - Wasatch Laboratories & 54 & UNIS & $\mathrm{CFN}$ & JNJ \\
\hline WST - West Pharmaceuticals & 1 & PNM & UNS & WEC \\
\hline XEL - Xcel Energy & 7 & ATI & RTI & NNDIF \\
\hline ZINC - Horsehead & 30 & CLC & CECE & FTEK \\
\hline
\end{tabular}

Note: The above table represents the associated companies to the causation company from which the chemical incident occurred. A thorough analysis was undergone to identify the most similar trading companies, based across a selection spectrum including size, business origins, location, number of employees, revenues and range of products. Multiple model codes exist for some companies in the sample âĂŞ linked directly with companies who had multiple chemical incidents between 2000 and 2014. The corresponding competitor companies remain the same throughout the sample. In multiple scenario cases, the parent company of postâĂŞtakeover is used. Prior to this, the stock price for the company that has been taken over is used. 
Table 2: Industrial accidents attributed to company violations and safety errors.

\begin{tabular}{|c|c|c|c|c|c|c|c|}
\hline Model & Data Source & Ticker & Disaster Type & Date & Location & Injuries & Fatalities \\
\hline 1 & CSB & WST & Fire \& Explosion & $29 / 01 / 2003$ & Kinston & 36 & 6 \\
\hline 2 & $\mathrm{LN}$ & ABLE & Explosion & $14 / 03 / 2003$ & New Jersey & 16 & 0 \\
\hline 3 & $\mathrm{CSB}$ & SIAL & Fire \& Explosion & $21 / 09 / 2003$ & Miami & 1 & 0 \\
\hline 4 & $\mathrm{CSB}$ & $\mathrm{BP}$ & Fire \& Explosion & $23 / 03 / 2005$ & Texas City & 180 & 15 \\
\hline 5 & RTN & TSN & Chemical Leak & $31 / 10 / 2006$ & South Hutchinson & 1 & 2 \\
\hline 6 & $\mathrm{CSB}$ & VLO & Fire \& Explosion & $16 / 02 / 2007$ & Sunray & 4 & 0 \\
\hline 7 & CSB & XEL & Asphyxiation & $02 / 10 / 2007$ & Georgetown & 3 & 5 \\
\hline 8 & $\mathrm{LN}$ & $\mathrm{BP}$ & Chemical Explosion & $14 / 01 / 2008$ & Houston & 0 & 1 \\
\hline 9 & $\mathrm{CSB}$ & IPSU & Fire \& Explosion & $07 / 02 / 2008$ & Port Wentworth & 42 & 14 \\
\hline 10 & $\mathrm{CSB}$ & PKG & Fire \& Explosion & $29 / 07 / 2008$ & Tomahawk & 1 & 3 \\
\hline 11 & RTN & DEDR.L & Fire \& Explosion & $20 / 11 / 2008$ & Tyler & 3 & 2 \\
\hline 12 & $\mathrm{CSB}$ & $\mathrm{VE}$ & Chemical Leak & $04 / 05 / 2009$ & West Carrollton & 2 & 0 \\
\hline 13 & $\mathrm{CSB}$ & $\mathrm{CAG}$ & Chemical Explosion & $09 / 06 / 2009$ & Garner & 25 & 4 \\
\hline 14 & RTN & $\mathrm{CF}$ & Chemical Exposure & $16 / 11 / 2009$ & Rosemount & 0 & 2 \\
\hline 15 & CSB & DD & Chemical Leak & $23 / 01 / 2010$ & Belle & 0 & 1 \\
\hline 16 & RTN & TSO & Fire \& Explosion & $02 / 04 / 2010$ & Anacortes & 0 & 7 \\
\hline 17 & $\mathrm{LN}$ & $\mathrm{BP}$ & Chemical Spill/Release & $20 / 04 / 2010$ & Texas & 2 & 0 \\
\hline 18 & CSB & DCI & Fire \& Explosion & $08 / 04 / 2011$ & Waikele & 1 & 5 \\
\hline 19 & $\mathrm{LN}$ & CW & Chemical Explosion & $22 / 05 / 2012$ & Arlington & 17 & 1 \\
\hline
\end{tabular}

Note: The above table represents the main industrial incidents included in this analysis that were found to have been attributed to company violations and safety errors. The ticker refers to the stock market identification code attributed to each company. The total number of injuries and fatalities have been taken from official reports obtained from the United States Chemical Safety Bureau (CSB) or from a thorough search of the LexusNexis database (LN). 
Table 3: Industrial accidents attributed to equipment failure.

\begin{tabular}{|c|c|c|c|c|c|c|c|}
\hline Model & Data Source & Ticker & Disaster Type & Date & Location & Injuries & Fatalities \\
\hline 20 & $\mathrm{LN}$ & CVX & Fire & $04 / 10 / 2001$ & Bakersfield & 1 & 0 \\
\hline 21 & CSB & $\mathrm{HON}$ & Chemical Leak & $20 / 07 / 2003$ & Baton Rouge & 8 & 0 \\
\hline 22 & CSB & $\mathrm{BP}$ & Fire \& Explosion & $28 / 07 / 2005$ & Texas City & 1 & 0 \\
\hline 23 & $\mathrm{LN}$ & JAH & Chemical Explosion & $14 / 09 / 2006$ & Columbia & 1 & 0 \\
\hline 24 & $\mathrm{LN}$ & TMO & Chemical Explosion & $30 / 03 / 2007$ & Logan & 1 & 0 \\
\hline 25 & $\mathrm{LN}$ & BRK.A & Explosion & $17 / 02 / 2008$ & Springville & 11 & 0 \\
\hline 26 & CSB & GT & Fire \& Explosion & $11 / 06 / 2008$ & Houston & 0 & 1 \\
\hline 27 & RTN & OXY & Chemical leak & $18 / 11 / 2008$ & Deer Park & 15 & 0 \\
\hline 28 & CSB & EAGLU & Fire \& Explosion & $12 / 01 / 2009$ & Woods Cross & 2 & 0 \\
\hline 29 & RTN & DOW & Chemical Explosion & $10 / 03 / 2010$ & Freeport & 1 & 0 \\
\hline 30 & $\mathrm{CSB}$ & ZINC & Fire \& Explosion & $22 / 07 / 2010$ & Monaca & 0 & 2 \\
\hline 31 & RTN & DOW & Chemical Explosion & $26 / 01 / 2011$ & Freeport & 2 & 0 \\
\hline 32 & RTN & DOW & Chemical Explosion & $29 / 06 / 2011$ & Freeport & 3 & 0 \\
\hline 33 & $\mathrm{LN}$ & OAS & Fire \& Explosion & $14 / 09 / 2011$ & North Dakota & 2 & 2 \\
\hline 34 & RTN & DHR & Fire & $14 / 11 / 2011$ & Dover & 5 & 0 \\
\hline 35 & RTN & CVX & Fire & $06 / 08 / 2012$ & Richmond & 14,003 & 0 \\
\hline 36 & RTN & $\mathrm{VLO}$ & Fire \& Explosion & $03 / 12 / 2012$ & Memphis & 3 & 1 \\
\hline 37 & $\mathrm{LN}$ & WLK & Chemical Explosion & $13 / 06 / 2013$ & Geismar & 73 & 1 \\
\hline
\end{tabular}

Note: The above table represents the main industrial incidents included in this analysis that were found to have been attributed to equipment failure. The ticker refers to the stock market identification code attributed to each company. The total number of injuries and fatalities have been taken from official reports obtained from the United States Chemical Safety Bureau (CSB) or from a thorough search of the LexusNexis database $(\mathrm{LN})$ 
Table 4: Industrial accidents attributed to human error.

\begin{tabular}{clllllcc}
\hline Model & Data Source & Ticker & Disaster Type & Date & Location & Injuries & Fatalities \\
\hline 38 & CSB & BP & Fire & $13 / 03 / 2001$ & Augusta & 0 & 3 \\
39 & RTN & KRFT & Chemical Leak & $23 / 12 / 2001$ & Maddison & 1 & 1 \\
40 & CSB & HON & Chemical Leak & $29 / 07 / 2003$ & Baton Rouge & 0 & 1 \\
41 & CSB & HON & Chemical Leak & $13 / 08 / 2003$ & Baton Rouge & 1 & 0 \\
42 & LN & PXP & Fire & $31 / 08 / 2004$ & Baldwin Hills & 1 & 0 \\
43 & CSB & MCS & Fire \& Explosion & $03 / 12 / 2004$ & Houston & 6 & 0 \\
44 & LN & UNP & Chemical Spill & $06 / 03 / 2005$ & Salt Lake City & 12 & 2 \\
45 & RTN & RAH & Explosion & $19 / 07 / 2005$ & Louisville & 0 & 0 \\
46 & CSB & 1301 & Fire \& Explosion & $06 / 10 / 2005$ & Point Comfort & 16 & 0 \\
47 & RTN & DEDR.L & Fire & $26 / 10 / 2005$ & Tyler & 1 & 0 \\
48 & CSB & VLO & Asphyxiation & $05 / 11 / 2005$ & Delaware & 0 & 2 \\
49 & RTN & NLC & Chemical Leak & $08 / 01 / 2007$ & Sugar Land & 14 & 0 \\
50 & RTN & DHR & Fire & $14 / 09 / 2007$ & Dover & 1 & 0 \\
51 & RTN & DOW & Chemical Spill & $13 / 11 / 2007$ & Freeport & 1 & 0 \\
52 & LN & NWSA & Chemical Leak & $17 / 12 / 2007$ & New York & 5 & 0 \\
53 & RTN & DOW & Chemical Spill & $11 / 04 / 2008$ & Freeport & 1 & 0 \\
54 & LN & WSHP & Chemical Explosion & $27 / 07 / 2009$ & Ogden & 3 & 0 \\
55 & RTN & VLO & Fire \& Explosion & $29 / 04 / 2010$ & Memphis & 1 & 0 \\
56 & RTN & DOW & Chemical Explosion & $17 / 05 / 2010$ & Freeport & 4 & 0 \\
57 & RTN & BON & Chemical Explosion & $12 / 06 / 2010$ & Oakfield & 1 & 0 \\
58 & RTN & DOW & Chemical Explosion & $13 / 09 / 2010$ & Freeport & 3 & 0 \\
59 & RTN & VLO & Fire \& Explosion & $06 / 03 / 2011$ & Norco & 1 & 1 \\
60 & RTN & GT & Fire \& Explosion & $11 / 06 / 2011$ & Houston & 7 & 1 \\
\hline
\end{tabular}

Note: The above table represents the main industrial incidents included in this analysis that were found to have been attributed to human error. The ticker refers to the stock market identification code attributed to each company. The total number of injuries and fatalities have been taken from official reports obtained from the United States Chemical Safety Bureau (CSB) or from a thorough search of the LexusNexis database $(\mathrm{LN})$. 
Table 5: Estimation results from the multivariate AR(1)-DCC-GARCH(1,1) model on industrial accidents caused by company violations and safety errors

\begin{tabular}{|c|c|c|c|c|c|c|c|c|c|c|c|c|}
\hline Ticker & $\mu_{0}$ & $\mu_{1}$ & $\mu_{2}$ & $c_{1}$ & $c_{2}$ & $c_{3}$ & $\rho_{1}$ & $\rho_{2}$ & $\rho_{3}$ & $\omega_{i}$ & $\alpha_{i}$ & $\beta_{i}$ \\
\hline 1. WST & $0.0008^{* *}$ & $0.0008^{* *}$ & $0.0008^{* * *}$ & $-0.001^{* *}$ & $0.0020^{* * *}$ & $0.0001^{* *}$ & $0.2917^{* * *}$ & $0.4808^{* * *}$ & $0.5014^{*}$ & $0.0000^{* * *}$ & $0.0944^{* * *}$ & $0.8574^{* * *}$ \\
\hline 2. ABLE & $0.0039 * *$ & -0.0006 & -0.0001 & -0.0011 & $0.0006 * *$ & $0.0003^{*}$ & 0.3275 & 0.3937 & 0.4172 & $0.0006 * * *$ & $0.1662^{* * *}$ & $0.6845^{* * *}$ \\
\hline 3. SIAL & 0.0004 & $0.0004^{* *}$ & 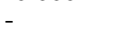 & 0.0004 & 0.0003 & $0.0004^{* *}$ & $1.4285^{* * *}$ & $1.1893^{* * *}$ & $1.6436^{* * *}$ & $0.0006^{* *}$ & $0.0443^{* * *}$ & $0.9461^{* * *}$ \\
\hline 4. $\mathrm{BP} \#$ & 0.0002 & $0.002^{* *}$ & $0.008^{* *}$ & $0.003^{* * *}$ & 0.003 & $0.009^{*}$ & $0.6444^{* * *}$ & $0.6563^{* * *}$ & $0.7154^{* * *}$ & $0.000^{* * *}$ & $0.5686^{* * *}$ & $0.9323 * * *$ \\
\hline 5. TSN & $0.0004^{*}$ & $0.0004 *$ & 0.0006 & $0.0012^{* *}$ & $0.0005^{* *}$ & $0.0018^{* *}$ & $0.4785^{* *}$ & $0.5814^{* *}$ & $0.3799^{* * *}$ & $0.0007 * *$ & $0.0415^{* * *}$ & $0.9436^{* * *}$ \\
\hline 6. VLO & $0.0007^{* *}$ & $0.0011^{* *}$ & -0.0003 & $0.0009^{* *}$ & $0.0016^{* *}$ & 0.0015 & $0.2779^{* * *}$ & $0.8532^{* * *}$ & $0.6651^{* * *}$ & $0.0016^{*}$ & 0.0714 & $0.8649 * *$ \\
\hline 7. XEL & 0.0003 & $0.0004^{*}$ & 0.0006 & -0.0004 & $-0.0007 * *$ & $0.0012^{* *}$ & $1.0881 * * *$ & $0.2742^{* * *}$ & $0.4188^{* * *}$ & $0.0004^{* *}$ & $0.0795^{* * *}$ & $0.9098^{* * *}$ \\
\hline 9. IPSU & $0.0010^{* *}$ & 0.0001 & $0.0018^{* *}$ & $0.0008^{* *}$ & $0.009^{* *}$ & $0.0007^{*}$ & $0.9166^{* * *}$ & $0.4481^{* * *}$ & $0.3354^{* * *}$ & $0.0065^{* * *}$ & $0.1718^{* * *}$ & $0.7639 * * *$ \\
\hline 10. PKG & $0.0004^{* *}$ & 0.0003 & $0.0004^{* *}$ & $0.0005^{* *}$ & $0.017^{* *}$ & $0.0003^{*}$ & $0.5348^{* * *}$ & $0.6722^{* * *}$ & $0.4993^{*}$ & $0.0007^{* * *}$ & $0.0428^{* * *}$ & $0.9471 * * *$ \\
\hline 11. DEDR & 0.0002 & 0.0001 & 0.0003 & $0.0006 * *$ & $0.0002^{* *}$ & 0.0000 & $0.7144^{* * *}$ & $1.1924^{* * *}$ & 0.1271 & 0.0003 & $0.0764^{* * *}$ & $0.9102 * * *$ \\
\hline 12. $\mathrm{VE}$ & 0.0006 & -0.0006 & -0.0006 & $0.0011^{* *}$ & 0.0005 & -0.0003 & $0.8853^{* * *}$ & $0.3361^{* * *}$ & $1.1434^{* * *}$ & 0.0006 & $0.0562^{* * *}$ & $0.9386^{* * *}$ \\
\hline 13. $\mathrm{CAG}$ & 0.0007 & $0.0002^{* *}$ & 0.0000 & 0.0000 & 0.0002 & $0.0007^{* *}$ & $0.0809^{* * *}$ & $0.3636^{* * *}$ & $0.7112^{* * *}$ & 0.0003 & $0.0293^{* * *}$ & $0.9681^{* * *}$ \\
\hline 14. $\mathrm{CF}$ & $0.0001 * *$ & $0.0005 *$ & 0.0006 & $0.0015^{* *}$ & -0.0002 & -0.0002 & $0.7166^{* *}$ & $0.6892^{* *}$ & $0.3562^{* *}$ & $0.0007 *$ & $0.0087^{* *}$ & $0.9821 * * *$ \\
\hline 15. DD & $0.0008^{* *}$ & $0.0004^{* *}$ & $0.0009^{* *}$ & 0.0001 & $0.0005^{* *}$ & 0.0006 & $0.7362^{* * *}$ & $0.5727^{* * *}$ & $0.9232^{* * *}$ & $0.0007 * *$ & $0.0851^{* * *}$ & $0.9018^{* * *}$ \\
\hline 16. TSO & $0.0015^{* *}$ & 0.0008 & $0.0021^{* *}$ & $0.0017^{* *}$ & 0.0019 & 0.0009 & $0.7902^{* * *}$ & 0.665 & $0.6479 * * *$ & $0.0012^{* *}$ & $0.0176^{* *}$ & $0.9309^{* * *}$ \\
\hline 18. DCI & $0.0002^{* *}$ & $0.0009^{* *}$ & 0.0000 & 0.0005 & $0.0006^{* *}$ & 0.0002 & $0.5798^{* * *}$ & $2.3099^{* *}$ & $0.2863^{* * *}$ & $0.0007 * *$ & $0.0768^{* * *}$ & $0.8839^{* * *}$ \\
\hline 19. CW & 0.0002 & -0.0001 & 0.0018 & 0.0001 & $0.0007^{* *}$ & $0.0003^{* *}$ & $0.7477^{* * *}$ & $0.6184^{* * *}$ & $0.3458^{* * *}$ & 0.0006 & $0.0631^{* * *}$ & $0.9165 * * *$ \\
\hline
\end{tabular}

Note: The above table reports the coefficients of the return and conditional variance equations as well as the DCC parameters of the incident company and its three leading industry competitors. $* * *, * *$ and $*$ denote the significance of the $\mathrm{GARCH}(1,1)$ estimates at the $1 \%, 5 \%$ and $10 \%$ levels respectively. 
Table 6: Estimation results from the multivariate AR(1)-DCC-GARCH(1,1) model on industrial accidents caused by equipment failure

\begin{tabular}{|c|c|c|c|c|c|c|c|c|c|c|c|c|}
\hline Ticker & $\mu_{0}$ & $\mu_{1}$ & $\mu_{2}$ & $c_{1}$ & $c_{2}$ & $c_{3}$ & $\rho_{1}$ & $\rho_{2}$ & $\rho_{3}$ & $\omega_{i}$ & $\alpha_{i}$ & $\beta_{i}$ \\
\hline 20. CVX & $0.0003^{* *}$ & 0.0008 & 0.0003 & 0.0001 & âÅŞ0.0001 & $0.0005^{* *}$ & $0.0524^{* *}$ & $0.7623^{* * *}$ & $1.6697^{* * *}$ & $0.0007^{* *}$ & $0.0814^{* * *}$ & $0.8994^{* * *}$ \\
\hline 21. HON & $.0002^{* *}$ & $0.0002^{* *}$ & $0.0002^{* *}$ & $0.0003^{* *}$ & $0.0002 *$ & 0.0001 & $0.9761 * * *$ & $0.6269^{* * *}$ & $0.6647^{* * *}$ & $0.0008^{* * *}$ & $0.0427^{* * *}$ & $0.9549^{* * *}$ \\
\hline 23. JAH & 0001 & 0.0004 & $0.0008^{* *}$ & $0.0007^{* *}$ & -0.0019 & 0.0002 & $0.6154^{* * *}$ & $0.1017^{* * *}$ & $0.1588^{* * *}$ & $0.0017^{* * *}$ & $0.1225^{* * *}$ & $0.8689^{* * *}$ \\
\hline 24. TMO & $0007 * *$ & $0.0001^{* *}$ & $0.0003^{*}$ & -0.0002 & 0.0001 & $0.0005^{* *}$ & $0.4958^{* * *}$ & $0.3884^{* * *}$ & $0.5477^{* * *}$ & $0.0012^{* * *}$ & $0.0879^{* * *}$ & $0.8910^{* * *}$ \\
\hline 25. BRK & $0.0001^{*}$ & k** & $0.0002 *$ & $-0.0004^{*}$ & $02 *$ & 0.0007 & $1.0150^{* * *}$ & $0.2968^{* * *}$ & $0.3155^{*}$ & $0.0005^{* *}$ & $0.1143^{* * *}$ & $0.8797^{* * *}$ \\
\hline 26. GT & $0002 * *$ & $0.0001^{* *}$ & 0.0005 & $0.0005^{* *}$ & 0.0007 & $0.0001^{* *}$ & $88^{* * *}$ & $0.2394^{* * *}$ & $0.4537^{* * *}$ & 0.0009 & $0.0338^{* * *}$ & $0.9507^{* * *}$ \\
\hline 27. OXY & $007^{* *}$ & ** & & & & $0 . c$ & & $78^{* * *}$ & $0.7313^{* * *}$ & $09^{* * *}$ & $576^{* * *}$ & $336^{* * *}$ \\
\hline 28. EAGL & 0.0001 & 0.000 & $04^{*}$ & 0.00 & 02 & & $0.1677^{* * *}$ & $0.2519^{* * *}$ & & 0.0000 & $0.1615^{* *}$ & $0.7889^{* * *}$ \\
\hline 29. DOW & & & & & ** & 0. & *** & ;*** & $0.7256^{* * *}$ & & $2^{* * *}$ & $313^{* * *}$ \\
\hline 30. ZINC & 0003 & 00 & 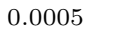 & * & $0002^{*}$ & $0.0005^{*}$ & $2^{* * *}$ & $0.9233^{* * *}$ & $0.4822^{* * *}$ & $0.0009^{* *}$ & $0.0422^{* * *}$ & $0.9515^{* * *}$ \\
\hline 33. OAS & $009^{*}$ & & $6 * *$ & ** & & $002 * *$ & F*** & $0.6342^{* * *}$ & $0.3499 * * *$ & 0.0009 & $0.0361^{* *}$ & $0.9433^{* * *}$ \\
\hline 34. DHR & 0001 & 0.0002 & 0.0001 & $0.0007^{* *}$ & $0.0003^{*}$ & 0.0003 & $0.8834^{* * *}$ & $0.1219 * * *$ & $0.5484^{* * *}$ & $0.0008^{* * *}$ & $0.0517 * * *$ & $0.9319^{* * *}$ \\
\hline 37. WLK & 0.0004 & $0.0001 *$ & 0.0006 & $-0.0023^{*}$ & $0.0011^{* *}$ & $0.0005^{* *}$ & $1.0586^{* * *}$ & $0.8755^{* * *}$ & $0.6111^{* * *}$ & $0.0009^{* *}$ & $0.0469^{* * *}$ & $0.9453^{* * *}$ \\
\hline
\end{tabular}

Note: The above table reports the coefficients of the return and conditional variance equations as well as the DCC parameters of the incident company and its three leading industry competitors. $* * *, * *$ and $*$ denote the significance of the $\mathrm{GARCH}(1,1)$ estimates at the $1 \%, 5 \%$ and $10 \%$ levels respectively. 
Table 7: Estimation results from the multivariate AR(1)-DCC-GARCH(1,1) model on industrial accidents caused by human error

\begin{tabular}{|c|c|c|c|c|c|c|c|c|c|c|c|c|}
\hline Ticker & $\mu_{0}$ & $\mu_{1}$ & $\mu_{2}$ & $c_{1}$ & $c_{2}$ & $c_{3}$ & $\rho_{1}$ & $\rho_{2}$ & $\rho_{3}$ & $\omega_{i}$ & $\alpha_{i}$ & \\
\hline$\overline{39 . \mathrm{KRFT}}$ & $0.0002^{* *}$ & $0.0003^{* *}$ & $0.0001^{*}$ & 0.0004 & $0.0004^{* *}$ & $0.0004^{*}$ & $0.5111^{* * *}$ & $0.3811^{* * *}$ & $0.3961^{* * *}$ & $0.0009^{* *}$ & $0.2399^{* *}$ & $0.5807^{* *}$ \\
\hline 42. PXP & 0.0001 & 0.0004 & 0.0007 & $0.0006^{* *}$ & 0.0009 & $0.0013^{* *}$ & $0.1355^{* *}$ & $0.4158^{* * *}$ & $0.5683^{* * *}$ & 0.0006 & 0.0100 & $0.8298^{* * *}$ \\
\hline 43. MCS & 0.0011 & 0.009 & $0.0002^{* *}$ & 0.0009 & $0.0002 *$ & $0.0001^{* *}$ & $0.4299^{* * *}$ & $0.7181^{* * *}$ & $0.6177^{* * *}$ & 0.0002 & $0.1483^{* * *}$ & $0.8013^{* * *}$ \\
\hline 44. UNP & $0.0007^{* *}$ & $0.0019^{* *}$ & $0.0007^{* *}$ & $0.0008^{* *}$ & 0.0007 & $0.0001 *$ & $0.7771^{* * *}$ & $0.3188^{* *}$ & $0.1884^{* *}$ & $0.0012^{* * *}$ & $0.062^{* * *}$ & $0.9248^{* * *}$ \\
\hline 48. NLC & $0.0005^{*}$ & $0.0005^{*}$ & $0.0002^{*}$ & $0.0003^{*}$ & $0.0007^{* *}$ & $0.0002 *$ & $0.5024 * * *$ & $0.2891 * * *$ & $0.6637^{* * *}$ & $0.0014^{* *}$ & $0.0588^{* * *}$ & $0.9173^{* * *}$ \\
\hline 52. NWSA & 0.0006 & 0.0004 & 0.0004 & $0.0001^{* *}$ & -0.0003 & $0.0012^{* *}$ & $0.4811^{* * *}$ & $0.1605^{*}$ & $0.3074^{* * *}$ & 0.0004 & $0.2238^{* *}$ & $0.6648^{* * *}$ \\
\hline 55. BON & $0.0003^{*}$ & $0.0003^{*}$ & $0.0003^{*}$ & -0.0001 & $0.0003^{* *}$ & $0.0004^{* *}$ & $0.0997^{* * *}$ & $0.7133^{* * *}$ & $0.6872^{* * *}$ & 0.0005 & $0.2487^{* * *}$ & $0.4127^{* * *}$ \\
\hline
\end{tabular}

Note: The above table reports the coefficients of the return and conditional variance equations as well as the DCC parameters of the incident company and its three leading industry competitors. $* * *, * *$ and $*$ denote the significance of the GARCH $(1,1)$ estimates at the $1 \%, 5 \%$ and $10 \%$ levels respectively. 
Table 8: GARCH model testing changes in dynamics conditional correlations of stock market returns after industrial accidents attributed to company violations and safety errors.

\begin{tabular}{|c|c|c|c|c|c|c|c|c|c|c|}
\hline Model & $\omega_{i j}$ & $\alpha_{1}$ & $\beta_{1}$ & $D M_{1}$ & $d_{1}$ & $M C d_{1}$ & $d_{2}$ & $M C d_{2}$ & $d_{3}$ & $M C d_{3}$ \\
\hline 1 & $0.0000^{* * *}$ & $0.0923^{* * *}$ & $0.8593^{* * *}$ & $0.0082^{* *}$ & 0.0003 & 2.04 & $0.0008^{* *}$ & 2.53 & $0.0211^{*}$ & 9.80 \\
\hline 2 & $0.0006^{* * *}$ & $0.1671^{* * *}$ & $0.6835^{* * *}$ & 0.0026 & $0.0007^{* * *}$ & 1.90 & $0.0023^{* * *}$ & 0.39 & $0.0005^{*}$ & 0.35 \\
\hline 3 & $0.0000^{* * *}$ & $0.0544^{* * *}$ & $0.9459^{* * *}$ & $0.0022^{* * *}$ & 0.0001 & 54.75 & $0.0021 *$ & 5.69 & $0.0026^{* * *}$ & 3.56 \\
\hline 4 & $0.0000^{* * *}$ & $0.0569 * * *$ & $0.9323^{* * *}$ & $0.0019 * * *$ & $0.0034^{*}$ & 87.60 & $0.0035 *$ & 422.33 & - & - \\
\hline 5 & $0.0000^{* * *}$ & $0.0414^{* * *}$ & $0.9438^{* * *}$ & $0.0029 *$ & 0.0006 & 22.19 & 0.0003 & 12.44 & $0.0027^{*}$ & 2.19 \\
\hline 6 & $0.0000^{* * *}$ & $0.0936^{* * *}$ & $0.7635^{* * *}$ & 0.0046 & 0.0012 & 1.08 & $0.0021^{* * *}$ & 46.83 & 0.0004 & 8.07 \\
\hline 7 & $0.0000^{* * *}$ & $0.0794^{* * *}$ & $0.9097^{* * *}$ & $0.0070^{* *}$ & $0.0008^{*}$ & 4.49 & $0.0009 * * *$ & 0.18 & 0.0004 & 0.88 \\
\hline 8 & $0.0000^{* * *}$ & $0.0567 * * *$ & $0.9324^{* * *}$ & $0.0014^{* * *}$ & 0.0002 & 87.60 & $0.0009 *$ & 422.33 & - & - \\
\hline 9 & $0.0000^{* * *}$ & $0.0915^{* * *}$ & $0.8585^{* * *}$ & $0.0106^{*}$ & $0.0015^{* *}$ & 0.53 & $0.0045^{* * *}$ & 0.11 & $0.0003^{* * *}$ & 0.19 \\
\hline 10 & $0.0000^{* * *}$ & $0.0427^{* * *}$ & $0.9471^{* * *}$ & $0.0055^{* * *}$ & 0.0015 & 20.21 & $0.0059 * * *$ & 7.16 & 0.0015 & 6.76 \\
\hline 11 & $0.0000^{* * *}$ & $0.0765^{* * *}$ & $0.9099 * * *$ & 0.0013 & $0.0099 * * *$ & 11.41 & 0.0008 & 0.78 & 0.0001 & 0.25 \\
\hline 12 & $0.0000^{* * *}$ & $0.0562^{* * *}$ & $0.9385^{* * *}$ & $0.0032^{* *}$ & 0.0007 & 8.94 & 0.0008 & 61.48 & 0.0016 & 9.06 \\
\hline 13 & $0.0000^{* * *}$ & $0.0293^{* * *}$ & $0.9681^{* * *}$ & $0.0006^{* * *}$ & 0.0049 & 0.23 & $0.0016^{*}$ & 138.40 & 0.0043 & 0.22 \\
\hline 14 & $0.0000^{* *}$ & $0.0092^{* *}$ & $0.9816^{* * *}$ & $0.0037^{*}$ & 0.0038 & 0.58 & 0.0013 & 2.82 & $0.0049^{* *}$ & 1.20 \\
\hline 15 & $0.0000^{* * *}$ & $0.0861^{* * *}$ & $0.9005^{* * *}$ & $0.0015^{* *}$ & $0.0014 *$ & 62.12 & 0.0003 & 6.52 & 0.0019* & 62.42 \\
\hline 16 & $0.0009^{* * *}$ & $0.0205^{* *}$ & $0.9292^{* * *}$ & $0.0043^{*}$ & 0.0007 & 9.67 & 0.0024 & 46.83 & $0.0007 * * *$ & 27.71 \\
\hline 17 & $0.0000^{* * *}$ & $0.0565^{* * *}$ & $0.9328^{* * *}$ & $0.0032^{* *}$ & 0.0001 & 87.60 & $0.0009 * * *$ & 422.33 & - & - \\
\hline 18 & $0.0000^{* * *}$ & $0.0769^{* * *}$ & $0.8838^{* * *}$ & $0.0005^{* * *}$ & 0.0011 & 0.36 & 0.0008 & 3.05 & 0.0032 & 0.10 \\
\hline 19 & $0.0000^{* * *}$ & $0.0648^{* * *}$ & $0.9145^{* * *}$ & $0.0043^{* *}$ & 0.0005 & 1.23 & 0.0016 & 2.94 & 0.0029 & 1.43 \\
\hline
\end{tabular}

Note: The above table reports the estimated coefficients of the GARCH model based on the conditional correlations between the incident company and its three largest competitors, represented as $d_{1}, d_{1}$ and $d_{3}$. $D M_{1}$ represents the GARCH volatility estimated coefficient of the incident company itself. $M C d_{1}, M C d_{2}$ and $M C d_{3}$ represent the estimated market capitalisation of the three largest competitor companies respectively at the time of the chemical incident. $* * *, * *$ and * denote the significance of the $\operatorname{GARCH}(1,1)$ estimates at the $1 \%, 5 \%$ and $10 \%$ levels respectively. 
Table 9: GARCH model testing changes in dynamics conditional correlations of stock market returns after industrial accidents attributed to equipment failure.

\begin{tabular}{|c|c|c|c|c|c|c|c|c|c|c|}
\hline Model & $\omega_{i j}$ & $\alpha_{1}$ & $\beta_{1}$ & $D M_{1}$ & $d_{1}$ & $M C d_{1}$ & $d_{2}$ & $M C d_{2}$ & $d_{3}$ & $M C d_{3}$ \\
\hline$\overline{20}$ & $0.0000^{* * *}$ & $0.0815^{* * *}$ & $0.8992^{* * *}$ & 0.0003 & 0.0007 & 87.62 & $0.0019^{* *}$ & 257.77 & $0.0037^{*}$ & 150.41 \\
\hline 21 & $0.0000^{* * *}$ & $0.0427^{* * *}$ & $0.9549 * * *$ & $0.0014^{* *}$ & 0.0011* & 88.75 & 0.0012 & 43.95 & 0.0011 & 93.63 \\
\hline 22 & $0.0000 * * *$ & $0.0568^{* * *}$ & $0.9323^{* * *}$ & $0.0003^{* *}$ & 0.0005 & 87.60 & 0.0006 & 422.33 & - & 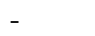 \\
\hline 23 & $0.0000^{* * *}$ & $0.1255^{* * *}$ & $0.8655^{* * *}$ & $0.0042^{* * *}$ & $0.0005^{*}$ & 28.58 & 0.0112 & 0.12 & 0.0094 & 0.03 \\
\hline 24 & $0.0000^{* * *}$ & $0.0879^{* * *}$ & $0.8909 * * *$ & 0.0001 & $0.0003^{* *}$ & 257.27 & $0.0002 * * *$ & 0.15 & 0.0001 & 5.12 \\
\hline 25 & $0.0000^{* * *}$ & $0.1168^{* * *}$ & $0.8770^{* * *}$ & $0.0025^{* * *}$ & $0.0039^{* * *}$ & 257.27 & 0.0013 & 91.53 & $0.0014 *$ & 238.22 \\
\hline 26 & $0.0000^{* * *}$ & $0.0342^{* * *}$ & $0.9503^{* * *}$ & $0.0018^{*}$ & 0.0001 & 28.26 & $0.0025^{*}$ & 1.90 & 0.0001 & 19.91 \\
\hline 27 & $0.0000^{* * *}$ & $0.0575^{* * *}$ & $0.9337^{* * *}$ & $0.0007^{*}$ & $0.0009 * *$ & 239.46 & $0.0014^{* *}$ & 21.40 & 0.0010 & 422.33 \\
\hline 28 & $0.0000^{* * *}$ & $0.1629^{* * *}$ & $0.7872^{* * *}$ & 0.0005 & $0.0031^{* * *}$ & 0.61 & 0.0007 & 1.45 & 0.0041 & 0.11 \\
\hline 29 & $0.0000 * * *$ & $0.0614^{* * *}$ & $0.9312^{* * *}$ & $0.0014 *$ & $0.0015^{* *}$ & 59.72 & 0.0012 & 62.42 & $0.0013^{*}$ & 422.33 \\
\hline 30 & $0.0000^{* * *}$ & $0.0425^{* * *}$ & $0.9511^{* * *}$ & $0.0048^{* *}$ & 0.0019 & 0.36 & $0.0101^{* *}$ & 3.05 & 0.0008 & 0.10 \\
\hline 31 & $0.0000 * * *$ & $0.0612^{* * *}$ & $0.9313^{* * *}$ & $0.0011^{* * *}$ & 0.0002 & 59.72 & $0.0013 *$ & 62.42 & 0.0004 & 422.33 \\
\hline 32 & $0.0000^{* * *}$ & $0.0616^{* * *}$ & $0.9309^{* * *}$ & $0.0016 *$ & $0.0009^{* * *}$ & 59.72 & 0.0017 & 62.42 & 0.0011 & 422.33 \\
\hline 33 & $0.0000 *$ & $0.0361^{* *}$ & $0.9431^{* * *}$ & 0.0019 & 0.0009 & 2.35 & $0.0073^{*}$ & 0.52 & 0.0041 & 0.95 \\
\hline 34 & $0.0000 * * *$ & $0.0517^{* * *}$ & $0.9321 * * *$ & 0.0002 & $0.0022 * * *$ & 19.19 & 0.0014 & 4.39 & $0.0009 * *$ & 1.50 \\
\hline 35 & $0.0000^{* * *}$ & $0.0813^{* * *}$ & $0.8995 * * *$ & $0.0014^{*}$ & $0.0008^{*}$ & 87.62 & 0.0012 & 257.77 & $0.0003^{* * *}$ & 150.41 \\
\hline 36 & 0.0000 & $0.0312^{* *}$ & $0.8222^{* * *}$ & $0.0018^{*}$ & $0.0028^{*}$ & 1.08 & 0.0019 & 46.83 & $0.0036^{* *}$ & 8.07 \\
\hline 37 & $0.0000^{* * *}$ & $0.0471^{* * *}$ & $0.9451^{* * *}$ & $0.0015 * * *$ & $0.0012^{* *}$ & 2.86 & 0.0009* & 12.03 & $0.0009 * * *$ & 422.33 \\
\hline
\end{tabular}

Note: The above table reports the estimated coefficients of the GARCH model based on the conditional correlations between the incident company and its three largest competitors, represented as $d_{1}, d_{1}$ and $d_{3} . D M_{1}$ represents the GARCH volatility estimated coefficient of the incident company itself. $M C d_{1}, M C d_{2}$ and $M C d_{3}$ represent the estimated market capitalisation of the three largest competitor companies respectively at the time of the chemical incident. $* * *, * *$ and * denote the significance of the $\operatorname{GARCH}(1,1)$ estimates at the $1 \%, 5 \%$ and $10 \%$ levels respectively. 
Table 10: GARCH model testing changes in dynamics conditional correlations of stock market returns after industrial accidents attributed to human error.

\begin{tabular}{|c|c|c|c|c|c|c|c|c|c|c|}
\hline Model & $\omega_{i j}$ & $\alpha_{1}$ & $\beta_{1}$ & $D M_{1}$ & $d_{1}$ & $M C d_{1}$ & $d_{2}$ & $M C d_{2}$ & $d_{3}$ & $M C d_{3}$ \\
\hline 38 & $0.0000^{* * *}$ & $0.0570^{* * *}$ & $0.9321^{* * *}$ & $0.0015^{* * *}$ & $0.0012^{* * *}$ & 87.60 & $0.0005^{* *}$ & 422.33 & - & - \\
\hline 39 & $0.0000^{*}$ & $0.2427^{* * *}$ & $0.5759 * * *$ & 0.0002 & $0.0001 *$ & 60.32 & 0.0004 & 138.40 & $0.0004^{* * *}$ & 10.48 \\
\hline 40 & $0.0000 * * *$ & $0.0814^{* * *}$ & $0.8994^{* * *}$ & $0.0001 *$ & 0.0002 & 88.75 & 0.0011 & 43.95 & $0.0006^{*}$ & 93.63 \\
\hline 41 & $0.0000^{* * *}$ & $0.0814^{* * *}$ & $0.8994 * * *$ & $0.0006^{* * *}$ & 0.0006 & 88.75 & 0.0004 & 43.95 & 0.0005 & 93.63 \\
\hline 42 & $0.0000^{* * *}$ & $0.0208^{*}$ & $0.8366^{* * *}$ & 0.0035 & 0.0019 & 54.75 & $0.0041^{*}$ & 17.01 & $0.0001 * * *$ & 12.88 \\
\hline 43 & $0.0000 * * *$ & $0.1476^{* * *}$ & $0.8023^{* * *}$ & $0.0015 * * *$ & $0.0009 * *$ & 2.25 & $0.0007 * * *$ & 0.79 & 0.0004 & 3.28 \\
\hline 44 & $0.0000^{* * *}$ & $0.0622^{* * *}$ & $0.9249 * * *$ & 0.0004 & $0.0008^{* * *}$ & 30.21 & 0.0010 & 12.42 & $0.0008^{*}$ & 32.34 \\
\hline 45 & $0.0000^{* * *}$ & $0.0716^{* * *}$ & $0.8971 * * *$ & 0.0015 & 0.0014 & 11.41 & $0.0009 *$ & 0.78 & $0.0010^{* * *}$ & 0.25 \\
\hline 46 & $0.0007^{* * *}$ & $0.0348^{*}$ & $0.7991^{* * *}$ & $0.0021 * * *$ & 0.0020 & 1.08 & $0.0029 *$ & 46.83 & 0.0008 & 8.07 \\
\hline 47 & $0.0000^{* * *}$ & $0.0708^{* * *}$ & $0.9011^{* * *}$ & $0.0024^{* * *}$ & $0.0011^{* *}$ & 0.75 & $0.0040 * * *$ & 0.03 & $0.0014^{* * *}$ & 0.16 \\
\hline 48 & $0.0000^{* * *}$ & $0.0613^{* * *}$ & $0.9312^{* * *}$ & $0.0005^{* * *}$ & 0.0003 & 19.19 & $0.0019 *$ & 4.39 & $0.0007^{*}$ & 1.50 \\
\hline 49 & $0.0000 * * *$ & $0.0592^{* * *}$ & $0.9169^{* * *}$ & $0.0005^{* * *}$ & 0.0001 & 59.72 & $0.0001 *$ & 62.42 & $0.0018^{* *}$ & 422.33 \\
\hline 50 & $0.0000^{* * *}$ & $0.0177^{* * *}$ & $0.9455^{* * *}$ & $0.0031 * * *$ & $0.0027 * * *$ & 31.61 & $0.0013^{* * *}$ & 7.80 & $0.0004^{* * *}$ & 15.33 \\
\hline 51 & $0.0000^{* * *}$ & $0.0611^{* * *}$ & $0.9314^{* * *}$ & $0.0015 *$ & $0.0011 *$ & 59.72 & 0.0003 & 62.42 & 0.0003 & 422.33 \\
\hline 52 & $0.0000^{*}$ & $0.2343^{* * *}$ & $0.6577^{* * *}$ & $0.0017^{* * *}$ & $0.0006^{* * *}$ & 8.92 & $0.0004^{* *}$ & 285.33 & $0.0006 * * *$ & 0.23 \\
\hline 53 & $0.0000^{* * *}$ & $0.0903^{* * *}$ & $0.7703^{* * *}$ & 0.0002 & 0.0001 & 1.08 & $0.0001 * * *$ & 46.83 & $0.0027^{* * *}$ & 8.07 \\
\hline 54 & $0.0000 * * *$ & $0.0612^{* * *}$ & $0.9313^{* * *}$ & 0.0003 & 0.0009 & 59.72 & 0.0002 & 62.42 & 0.0006 & 422.33 \\
\hline 55 & $0.0000^{* * *}$ & $0.0319 * * *$ & $0.8733^{* * *}$ & $0.0009 * * *$ & $0.0007^{* * *}$ & 0.35 & 0.0011 & 0.11 & 0.0008 & 9.23 \\
\hline 56 & $0.0000^{* * *}$ & $0.0613^{* * *}$ & $0.9312^{* * *}$ & $0.0019 * * *$ & $0.0016^{*}$ & 59.72 & 0.0009 & 62.42 & $0.0012^{* *}$ & 422.33 \\
\hline 57 & $0.0000^{* * *}$ & $0.2494^{* * *}$ & $0.7114^{* * *}$ & 0.0002 & $0.0029^{* *}$ & 1.08 & 0.0001 & 46.83 & $0.0016^{* * *}$ & 8.07 \\
\hline 58 & $0.0000^{* * *}$ & $0.0307^{* *}$ & $0.8171^{* * *}$ & $0.0014^{* *}$ & 0.0011 & 28.26 & 0.0022 & 1.90 & $0.0043^{*}$ & 19.91 \\
\hline 59 & $0.0000 * * *$ & $0.07191^{* * *}$ & $0.9170^{* * *}$ & 0.0015 & $0.0019 * * *$ & 3.64 & $0.0008^{* * *}$ & 54.30 & 0.0007 & 10.93 \\
\hline 60 & $0.0000^{* * *}$ & $0.04288^{* * *}$ & $0.9215^{* * *}$ & $0.0008^{* * *}$ & $0.0011^{* *}$ & 21.45 & $0.0007^{*}$ & 13.18 & $0.0001^{* * *}$ & 7.22 \\
\hline
\end{tabular}

Note: The above table reports the estimated coefficients of the GARCH model based on the conditional correlations between the incident company and its three largest competitors, represented as $d_{1}, d_{1}$ and $d_{3} . D M_{1}$ represents the GARCH volatility estimated coefficient of the incident company itself. $M C d_{1}, M C d_{2}$ and $M C d_{3}$ represent the estimated market capitalisation of the three largest competitor companies respectively at the time of the chemical incident. $* * *, * *$ and * denote the significance of the $\operatorname{GARCH}(1,1)$ estimates at the $1 \%, 5 \%$ and $10 \%$ levels respectively. 